\title{
Single Piece Dental Implant: A Remedy for Atrophic Ridges: Review
}

\author{
Shakhawan M. Ali1 ${ }^{*}$, Payman Kh. Mahmud², Kawan S. Othman³, Abduljaleel A. Samad4 \\ ${ }^{1}$ Department of Oral and Maxillofacial Surgery, School of Medicine, College of Dentistry, University of Sulaimani, Sulaymaniyah, \\ Kurdistan Region, Iraq \\ ${ }^{2}$ Department of Oral and Maxillofacial Medicine, Shar Teaching Hospital, Sulaymaniyah, Kurdistan Region, Iraq \\ ${ }^{3}$ Department of Prosthodontic, School of Medicine, College of Dentistry, University of Sulaimani, Sulaymaniyah, \\ Kurdistan Region, Iraq \\ ${ }^{4}$ Department of Oral Surgery, College of Dentistry, Hawler Medical University, Erbil, Kurdistan Region, Iraq \\ Email: *shakhawandr@hotmail.com, papykhalid@rocketmail.com
}

How to cite this paper: Ali, S.M., Mahmud, P.Kh., Othman, K.S. and Samad, A.A. (2019) Single Piece Dental Implant: A Remedy for Atrophic Ridges: Review. International Journal of Otolaryngology and Head \& Neck Surgery, 8, 271-282.

https://doi.org/10.4236/ijohns.2019.86025

Received: September 1, 2019

Accepted: November 19, 2019

Published: November 22, 2019

Copyright (c) 2019 by author(s) and Scientific Research Publishing Inc. This work is licensed under the Creative Commons Attribution International License (CC BY 4.0).

http://creativecommons.org/licenses/by/4.0/

\begin{abstract}
Implant placement in severely atrophic jaws is especially challenging because of the poor quality and quantity of the future implant bed. Although various bone augmentation procedure like ridge augmentation, sinus lift these procedures are possible today but it may lead to surgical morbidity they increase the risks and costs of dental implant treatment as well as the number of necessary operations. Also sometimes the patient is not agreeing for such extensive surgical procedures, according to the well-known implantological rules for dental restorations, crestal implants are indicated in situations when an adequate vertical bone supply is given but single piece dental implant (basal implants) is a viable treatment option derives support from the basal bone area which usually remains free from the infection and less prone to resorption.
\end{abstract}

\section{Keywords}

Single Piece Dental Implant (Basal Implants), Crestal Implants, Orthopaedic Implants, Atrophied Alveolar Ridge

\section{Introduction}

Rehabilitation the edentulous maxilla or mandible with implants has become a normal predictable treatment today but successful implant placement needs sufficient bone to be available (at least $13-15 \mathrm{~mm}$ length and $5-7 \mathrm{~mm}$ width) [1] [2]. Implant placement in severely atrophic jaws is especially challenging because of the poor quality and quantity of the future implant bed [3]. Calvarial or 
iliac bone grafts, mental nerve displacement, all on four, nerve bypass and sinus lift procedures are often used to overcome the initially unfavorable anatomical and mechanical conditions [4] [5] [6]. Despite acceptable success rates, these approaches involve unpredictable degrees of morbidity at the donor and/or recipient sites [7] Furthermore, patients are sometimes reluctant to undergo such procedures [8].

The conventional crestal implants are indicated in situations when an adequate vertical and horizontal bone must be available if not the prognosis is not good as soon as augmentation become part of the treatment plan. Augmentation procedures tend to increase the risks and costs of dental implant treatment as well as the number of necessary operations [1]. To avoid these procedures the other viable option for replacement in atrophic jaws is to change the implant design. Two very successful implant designs and protocols have been demonstrated in the past few decades for replacement in atrophic jaws which are Mini Dental Implants and Basal Implants [9].

Basal implant (single piece dental implant) also known as bicortical implant or just cortical implant is a modern implant system which utilizes the basal cortical portion of the jaw bones for retention of the dental implants which are uniquely designed to be accommodated in the basal cortical bone areas. The basal bone provides excellent quality cortical bone for retention of these unique and highly advanced implants. Because basal implant includes the application of the rules of orthopedic surgery, the basal implants are also called as "orthopaedic implant". Dental implants when placed in this bone can also be loaded with teeth immediately. This science is already proved in orthopedic implants (Hip/Knee replacements). Once the patient is fitted with the artificial joint patient is asked to start using it immediately [10].

This article reviews literature of using basal implants and the differences that exist between basal implants and crestal implants in rehabilitation of atrophied edentulous jaws (Table 1) [11], types of basal implants, drawbacks of conventional implants, advantages disadvantages and complication of basal implants.

Table 1. Comparison of conventional with single piece dental implants [11].

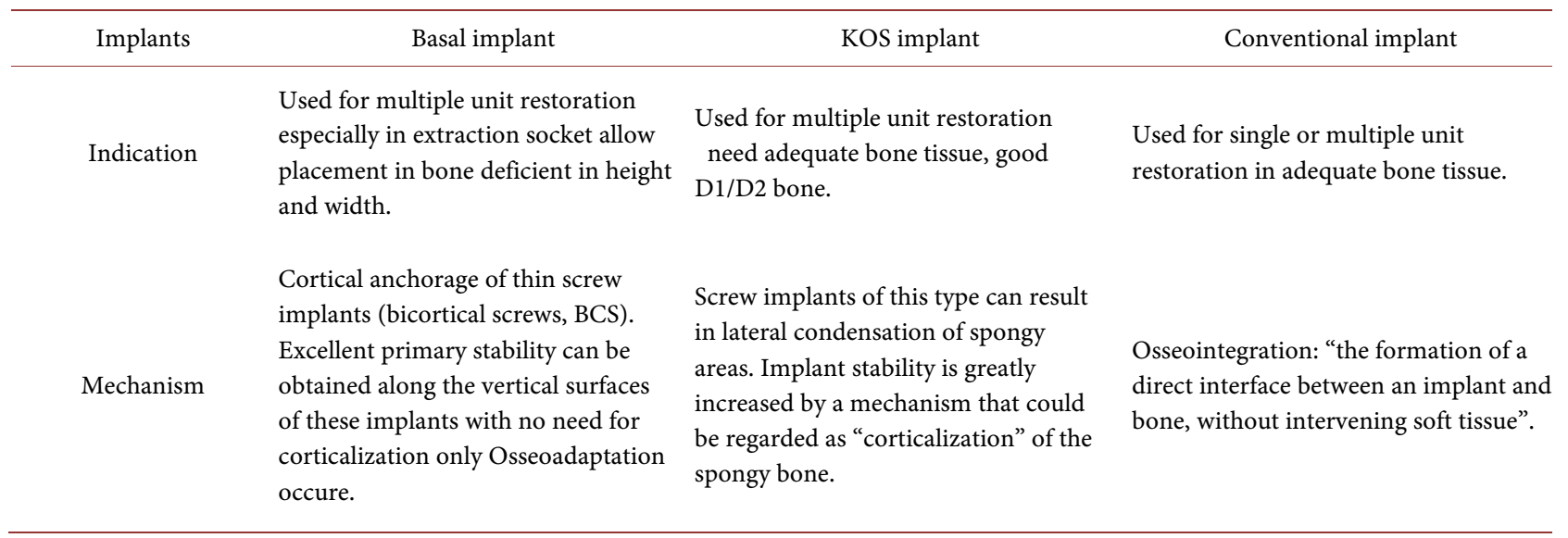




\section{Continued}

\begin{tabular}{|c|c|c|c|}
\hline Basic design & Immediate loading 72 hours & Immediate loading 72 hours & Delayed loading 3 - 6 months \\
\hline Implant procedure & $\begin{array}{l}\text { Single sitting surgical procedure and } \\
\text { very often flapless (no open surgical } \\
\text { procedures are necessary). Implant } \\
\text { procedures are less time consuming } \\
\text { than that required for bridgework. }\end{array}$ & $\begin{array}{l}\text { Single sitting surgical procedure and } \\
\text { very often flapless (no open surgical } \\
\text { procedures are necessary). Implant } \\
\text { procedures are less time consuming than } \\
\text { that required for bridgework. }\end{array}$ & $\begin{array}{l}\text { Very often more complex surgical } \\
\text { procedures are necessary, spread over } 2 \\
\text { or } 3 \text { sittings in a period of } 3 \text { - } 6 \text { months } \\
\text { (Implant placement, Healing Screw } \\
\text { placement \& Abutment Placement). }\end{array}$ \\
\hline Cost & Very cost effective & Very cost effective & Expensive \\
\hline $\begin{array}{l}\text { From the patient } \\
\text { point of view }\end{array}$ & Less complex placement procedure & Less complex placement procedure & more complex placement procedure \\
\hline Eligibility to patient & Almost every one & Almost every one & $\begin{array}{l}\text { No suitable for diabetic, Smoker and } \\
\text { patient with uncontrolled periodontitis }\end{array}$ \\
\hline Size and design & $\begin{array}{l}\text { Wide range of size and design are } \\
\text { available }\end{array}$ & $\begin{array}{l}\text { Wide range of size and design are } \\
\text { available }\end{array}$ & $\begin{array}{l}\text { limited range of size and design are } \\
\text { available }\end{array}$ \\
\hline Bone used & $\begin{array}{l}\text { Basal bone more dense, mineralized } \\
\text { and less prone to bone resorption }\end{array}$ & $\begin{array}{l}\text { Basal bone more dense, mineralized } \\
\text { and less prone to bone resorption }\end{array}$ & $\begin{array}{l}\text { Crestal alveolar bone, bone is less } \\
\text { quality and is more prone to resorption }\end{array}$ \\
\hline Additional surgery & No need bone augmentation sins lift.. & No need bone augmentation sins lift... & $\begin{array}{l}\text { Most time need another additional } \\
\text { surgery }\end{array}$ \\
\hline $\begin{array}{l}\text { Prosthodontic } \\
\text { procedures }\end{array}$ & $\begin{array}{l}\text { Very simple. Conventional } \\
\text { impressions of the implants can be } \\
\text { made just as is the case with routine } \\
\text { bridgework. Very less chairside time. }\end{array}$ & $\begin{array}{l}\text { Very simple. Conventional impressions } \\
\text { of the implants can be made just as } \\
\text { is the case with routine bridgework. } \\
\text { Very less chairside time. }\end{array}$ & $\begin{array}{l}\text { Requires more complex procedures } \\
\text { and chair side time. }\end{array}$ \\
\hline
\end{tabular}

\subsection{Rationale of Using Basal Implants}

Alveolar bone (crestal bone) of the jaw less dense gradually starts getting resorbed and receeds once the teeth are lost. The bone which ultimately remains after regression of the alveolar bone following loss of teeth is the basal bone which lies below the alveolar bone. This basal bone is less prone to bone resorption and infections. It is highly dense, corticalized and offers excellent support to implants. The conventional implants are placed in the crestal alveolar bone which comprises of bone of less quality and is more prone to resorption. The basal bone is less prone to bone resorption because of its highly dense structure. The implants which take support from the basal bone offer excellent and long lasting solution for tooth loss. At the same time, load bearing capacities of the cortical bone are many times higher than those of the spongious bone. This rationale stems from orthopedic surgery and from the experience that cortical areas are essential, since, they are resistant to resorption [12].

\subsection{Classification of Single Piece Dental Implant (Basal Implant) Based on Morphology [9]}

There are four basic types of basal implants: 
1) Screw Form

2) Disk Form

3) Plate Form

4) Other Forms:

1) Screw Form (Figure 1)

a) Compression Screw Design (KOS Implant)

b) Bi-Cortical Screw Design (BCS Implant)

c) Compression Screw + Bi-Cortical Screw Design (KOS Plus Implant)

2) Disk Form (Figure 1)

a) Basal Osseo-integrated Implant (BOI)

b) Trans-Osseous Implant (TOI)

c) Lateral Implant

3) Plate Form

a) BOI-BAC Implant

b) BOI-BAC2 Implant

4) Other Forms

a) TPG Implant (Tuberopterygoid)

b) ZSI Implant (Zygoma Screw)

\subsection{Morphology of Basal Implant}

The BOI (Basal Osseo Integrated) and BCS (Basal Cortical Screw) implant being produced today has a smooth and polished surface as it was found that polished surfaces are less prone to inflammation (mucositis, periimplantitis) than rough surfaces. The KOS and KOS Plus implants are surface treated (sand and grit blasting with subsequent acid etching), however, the implant neck is kept highly polished in KOS implant. In the KOS Plus implant, its neck and the basal cortical

KOS SERIES
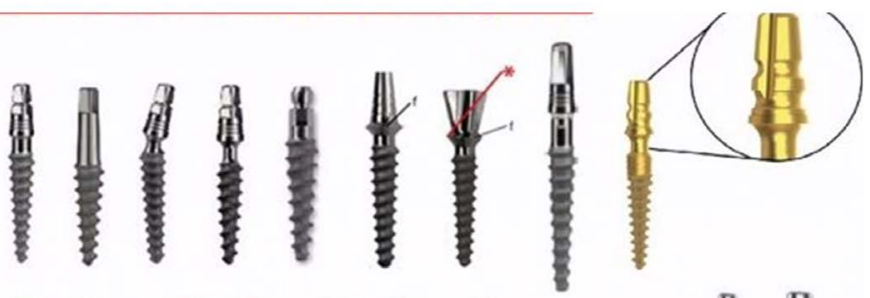

BCS SERIES
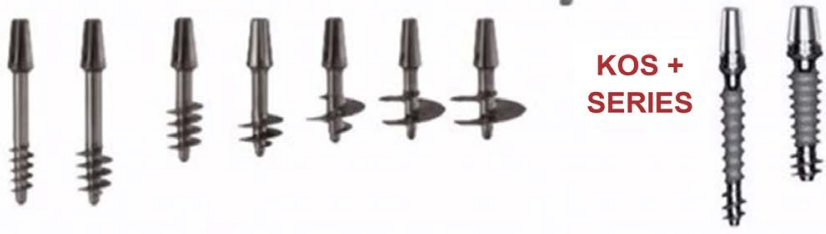

ZYGOMATIC
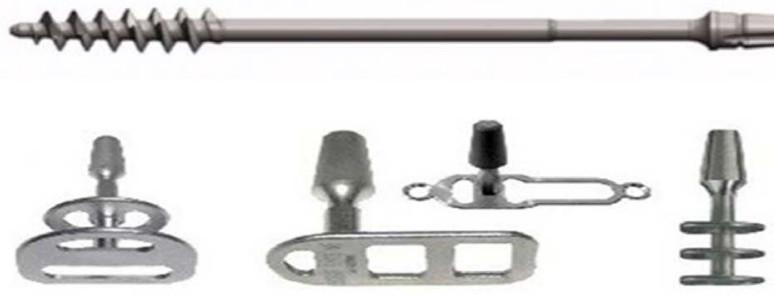

Figure 1. Types of single piece dental implant. 
screw part are kept heavily polished [13] [14] [15] (Figure 2).

BOI (Lateral Basal Implants) is inserted from the lateral aspect of the jaw bone and it requires minimum bone height of $3 \mathrm{~mm}$ and that means virtually every patient can be treated without bone grafting. Because bone grafting is avoided, risk groups, such as smokers and diabetics, can successfully receive these implants. Wide basal disk of the implant is stabilized into both facial as well as lingual strong cortices deep into the resorption and infection resistant zone (well deep from the crest) which guarantees safe load transmission and osseointegration. Its iso-elastic (flexible) design make it possible to connect its prosthesis to the firm and healthy natural teeth in selective cases which avoid the necessity of extraction of healthy teeth and also save the cost of the treatment. The neck of this implant can be bended to make multiple implant heads parallel for passive seating of the prosthesis and also to seat the prosthesis in the most suitable occlusion line. Masticatory load transmission is confined to the horizontal implant segments and, essentially, to the cortical bone structures [13].

BCS (Screw Basal Implant) is inserted like a conventional implant, but it transmits loads only into the opposing deep cortical bone that means virtually every patient can be treated without bone grafting. Because bone grafting is avoided, also risk groups, such as smokers and diabetics, can successfully receive these implants. Strictly cortical anchorage of the implant guarantees for safe load transmission and osseointegration. Minimal invasive implant placement (mostly without any flap and suture) the neck of this implant can be bended to make multiple implant heads parallel for passive seating of the prosthesis and also to seat the prosthesis in the most suitable occlusion line. These implants are also heavily polished and are flapless implants with a very small mucosal penetration diameter [10].

Compressive implant (KOS) is a single-component one piece screw type basal implants with a compression thread, it is used for multiple unit restoration with immediate loading in the upper and lower jaw, it can be used in combination

Conventional $2 / 3$ piece rough surface implant

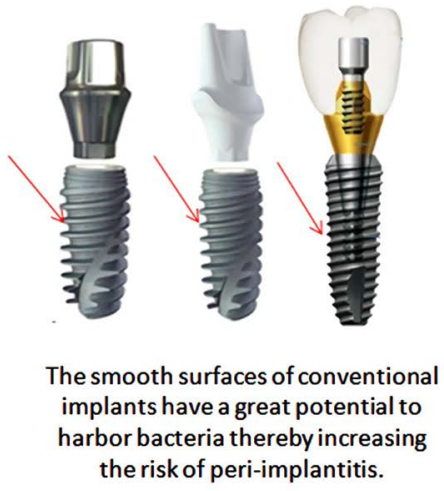

Figure 2. Implant surface.

\section{Smooth surface, single piece basal implants}

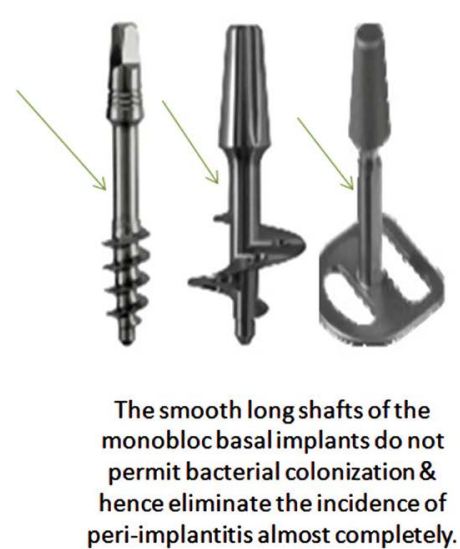


with other BCS basal implants (KOS Plus Implant) and allows flap and flapless placement. The first approach relies on the compression screw principle. Screw implants of this type can result in lateral condensation of spongy areas. Implant stability is greatly increased by a mechanism that could be regarded as "corticalization" of the spongy bone (KOS) [13].

\subsection{Parts of Basal Implants (Figure 3)}

The basal implants are single piece implants in which the implant and the abutment are fused into one single piece. This minimizes the failure of implants due to interface problems, the connections which exists in conventional two and three piece implants.

Surface of the implants:

polished surface;

stops bacteria and plaque from adhering to the implant neck or body.

Body of the Implants:

the thin implant body is combined with wide thread turns that enhances the vascularity around the implant and increases the bone implant contact.

Neck of the Implant:

the abutment can be bent by 15 - 25 degrees depending upon the length of the implant, provided the implant is placed in dense corticated bone;

> the polished surface protects the implant surface from bacterial attachment [1].

\section{Draw Backs with Conventional Root form Implant [16]}

1) Requires large amount of bone.

2) Require wider bone at crest to accommodate its neck which usually found lacking in many cases because of bone loss.

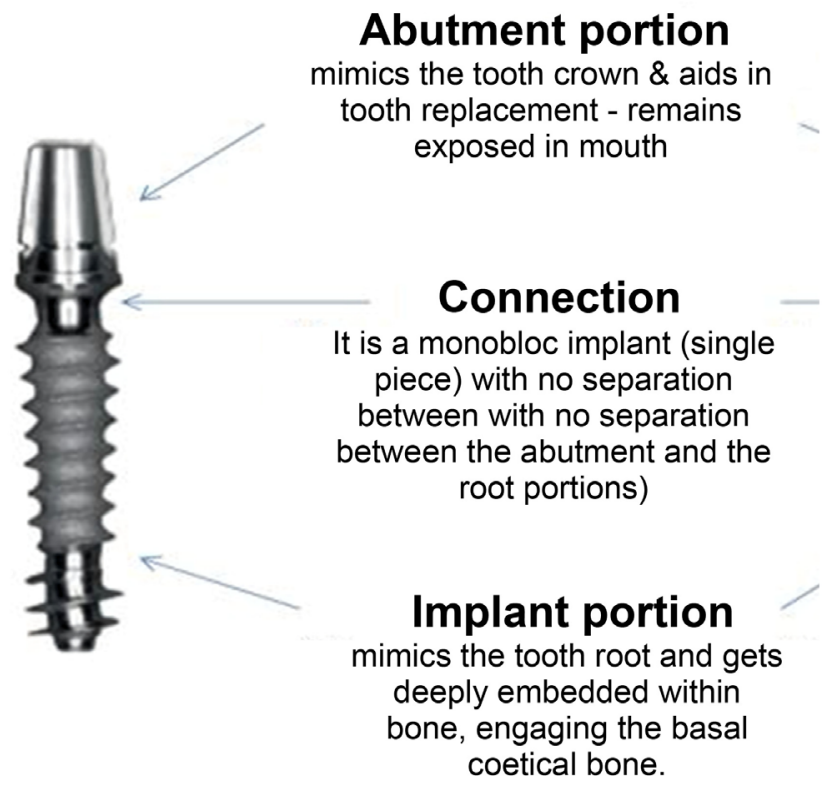

Figure 3. Parts of single piece dental implant. 
3) Mostly require bone augmentation procedures at the time or before the implant insertion which increase the cost, surgery time, no. of surgeries and treatment span.

4) Most part of the implant is placed into the poor density spongy bone which cannot be loaded immediately-may require healing time up to 3 - 8 months.

5) Because of vital structures such as maxillary sinus and mandibular canals in the back region of jaws, these implants may require large amount of bone augmentations (sinus augmentation, block grafting, nerve repositioning), multiple surgical steps, higher cost and longer healing times.

6) Has a screw connection which may lead to future screw loosening/screw breakage problems under the prosthesis.

7) Sensitive to infection-Theses implants have rough surface which is prone to collect infection once exposed to oral environment or placed at the infected region. Hence these implants cannot be placed into the infected tooth socket.

8) Being rough surface, these implants are prone to peri-implantitis.

9) Crestal bone loss-maximum stress/load comes on the bone crest which may cause crestal bone loss.

10) Wide neck diameter and rough surface of these implants require thick, keratinized and stable/non mobile gums around its neck to avoid the problems such as soft tissue.

\section{Surgical Technique}

Unlike conventional implants basal implants have a different surgical approach. The technique is simple and easy to execute and does not involve extensive drilling of bone thus avoiding thermal injury [13]. Throughout the surgery the mode of irrigation used is external and usually for almost any case a single pilot osteotomy with a "Pathfinder Drill" is sufficient for KOS, KOS Plus and BCS implants, the kit also consists of manual drills for a controlled osteotomy preparation [17] [18].

Basal implantologists do not advocate raising a flap for these implants as it results in a decreased blood supply and also because of the design of these implants raising a flap is pointless, another factor to be considered is the immediate loading of these implants; a sutured site is not a favorable area to receive an immediate prosthesis [13] [17] [18].

For the BOI implant the approach towards the bone is gained by raising a flap laterally and cutting into the bone with disk drills of required size in a lateral direction to form a " $T$ " shaped osteotomy. The implant consequently is placed laterally and the flap is closed over it [19].

\subsection{Indications [20]}

1) All kinds of situations when several teeth are missing or have to be extracted.

2) When the procedure of 2-stage implant placement or bone augmentation has failed.

3) In cases of severe bone deficiency either horizontal or vertical. 


\subsection{Contraindications}

1) Special Cases: Cases where bilateral equal mastication cannot be arranged, e.g. when chewing muscles or their innervations are partly missing (these cases may lead to problems under immediate load protocols).

2) Medical conditions: There are a number of medical conditions that preclude the placement of dental implants. Some of these conditions include: Recent myocardial infarction (heart attack) or cerebrovascular accident (stroke), Immunosuppression (a reduction in the efficacy of the immune system).

3) Medicines: A dentist will need a complete listing of all of the medicines and supplements that their patient takes. Drugs of concern are those utilized in the treatment of cancer, drugs that inhibit blood clotting and bisphosphonates (a class of drugs used in the treatment of osteoporosis).

\subsection{Advantages of Basal Implants [20]}

1) Safe load transmission in basal bone-Load transmission is deep in the infection free basal bone. In conventional root form implant, load transmission is near the area of bacterial attack. Cortical bone is resorption resistant due to higher mineralisation.

2) Less incidence of peri-implant infections-Implant surface is polished in basal implants and also the mucosal penetration diameter is less as compared to conventional dental implants.

3) Patient's own alveolar bone is required-Basal implants require the patient's own alveolar bone and no bone augmentations are required. All patients have sufficient basal bone horizontally even if vertically height is reduced. Also the duration of treatment is reduced as bone augmentations require certain amount of time for healing.

4) Immediate loading-Extremely good patient acceptance is obtained with basal implants as immediate loading is possible. There is no edentulous phase and immediate dentures are not required.

5) One stage procedure-Extractions and implant placement can be carried out in one appointment even if the teeth are periodontally infected.

6) Low demand for patient compliance.

\subsection{Disadvantages with Basal Implants [21]}

1) Compromised aesthetics with single tooth replacement.

2) Skilled surgeon with sound anatomic knowledge is important to carry out successful surgery.

3) Excess sound bone reduction in cases of good bone support.

4) A phenomenon called as overload osteolysis can be seen if load distribution is not done properly.

BOI-BAC Implant, BOI-BAC2 Implant [22] is onlay miniplate integrated implant marketed as BAC and BAC2 (not to be confused with their classical lateral osteotomy BOI implant) used in severely atrophied area as asubperiosteal implant retaining by screws (Figure 4). 
Tuberopterygoid (TPG) Screws: These implants are placed in the pterygoid bone and aid in providing additional support to the prosthesis. These are used in conjunct with Sinus Section technique and are placed at $20^{\circ}-45^{\circ}$ in the bone and the angulation between BOI implant and TPG screw should not exceed $90^{\circ}$ otherwise prosthesis placement becomes difficult (Figure 5).

Zygomatic Screw Implant (ZSI): These are zygomatic implants that are placed in the zygomatic bone and like the BCS implant these also have sharp edged cortical screws that gain bicortical support (Figure 6).

\section{$\mathrm{BOI}^{\circ} \mathrm{BAC} \quad \mathrm{BOI}^{\bullet} \mathrm{BAC2}$}
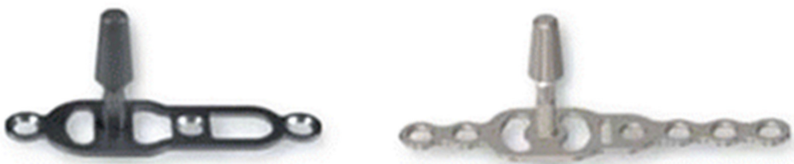

Figure 4. BOI-BAC implant, BOI-BAC2 implant.

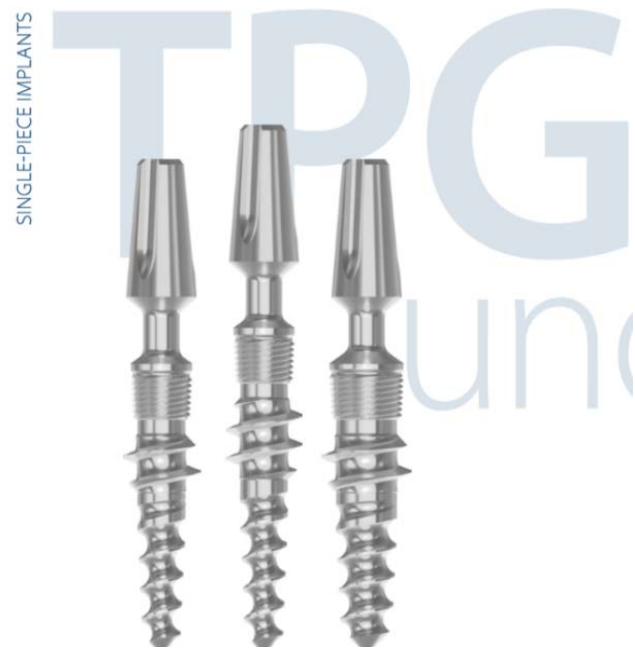

Figure 5. Pterygoid implant.

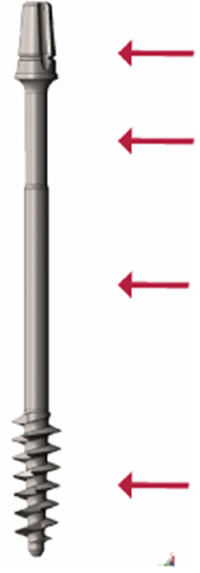

Single piece abutment

Long thin bendable neck

Strong polished shaft.

Apical polished threads to engage zygomatic buttress

Figure 6. Zygomatic screw implant. 


\section{Conclusion}

Developments of basal implants had given positive hope for the patients with atrophied ridges which can be rehabilitated not only by avoiding augmentation procedures, time and cost but also by immediately loading of the prosthesis making them more confident and socialize normally. More than $90 \%$ of the available Implant system all around the world follows system of crestal implants. Advocates of Basal Implant systems call it to be a better alternative to crestal implants in terms of ability to restore almost any type of case, shortened treatment time, less chance of failure. However, the long term results are yet to be proven. The whole concept is based upon the fact that basal bone is the most stable of all the bones available for Implants and that its resorption rate is virtually nil. Also to add is the chances of failure due to infection is also greatly reduced since the Implant takes its primary retention from the site which is very far from the surgical area. Despite of the data available on their success in treating a variety of cases these implants have gained little trust among conventional implantologists, it seems further research and development and more concrete data on clinical cases are required to prove their efficacy as a replacement to conventional implants. Technique of placing basal implants definitely requires a skillful operator with a sound knowledge of anatomy. Complications are rare but can be fatal if the procedure is not performed properly.

\section{Sources of Funding}

This work is performed solely by the authors of this manuscript. Nobody else participated in preparation or financial aid of this work. We just spent extra time to collect the data and put it together in the form of research.

\section{Ethical Approval}

Here in Iraq, we do not have committees or organizations for ethical approval. Taking informed consent is the only standard ethical process within hospital permission rules because all hospitals in Iraq are teaching governmental hospitals therefore informed consent is taken before doing any procedure or publishing the information of any patient.

\section{Conflicts of Interest}

The authors declare no conflicts of interest regarding the publication of this paper.

\section{References}

[1] Yadav, R.S., Sangur, R., Mahajan, T., Rajanikant, A.V., Singh, N. and Singh, R. (2015) An Alternative to Conventional Dental Implants: Basal Implants. Rama University Journal of Dental Sciences, 2, 22-28.

[2] Misch, C.E. (1993) Contemporary Implant Dentistry. Mosby, St. Louis.

[3] Scortecci, G., Misch, C.E. and Benner, K.U. (2001) Implants and Restorative Denti- 
stry. Martin Dunitz, London, 79-85.

[4] Shakhawan, M.A., Zanyar, M.A., Rebwar, A.H., Hawbash, O.M., Rozhyna, P.K. and Payman, K.M. (2019) All-on-Four Treatment Concept in Dental Implants: A Review Articles. Surgery \& Case Studies. Open Access Journal, 2, 175-179. https://doi.org/10.32474/SCSOAJ.2019.02.000142

[5] Neamat, A.H., Ali, S.M., Boskani, S.W. and Mahmud, P. (2017) An Indirect Sinus Floor Elevation by Using Piezoelectric Surgery with Platelet-Rich Fibrin for Sinus Augmentation: A Short Surgical Practice. International Journal of Case Reports, 8 , 380-384. https://doi.org/10.5348/ijcri-201752-CR-10791

[6] Misch, C.E., Qu, Z. and Bidez, M.W. (1999) Mechanical Properties of Trabecular Bone in the Human Mandible. Implications of Dental Implant Planning and Surgical Placement. Journal of Oral and Maxillofacial Surgery, 57, 700-706. https://doi.org/10.1016/S0278-2391(99)90437-8

[7] Misch, C.E. (2008) Contemporary Implant Dentistry. Mosby Elsevier, St Louis, 1034-1035.

[8] Odin, et al. (2012) Rehabilitation of Severely Atrophic Jaws Using Basal Disk Implants. Journal of Oral Implantology, 38, 611-616.

[9] Gupta, A.D., Verma, A., Dubey, T. and Thakur, S. (2017) Basal Osseointegrated Implants: Classification and Review. International Journal of Contemporary Medical Research, 4, 2329-2335.

[10] Ihde, S. (2009) Comparison of Basal and Crestal Implants and Their Modus of Application. Smile Dental Journal, 4, 36-46.

[11] Ali, S.M., Othman, K.S., Samad, A.A. and Mahmud, P.K. (2019) Comparison between Basal and Conventional Implants as a Treatment Modality in Atrophied Ridges. Journal of Dental Implant Research, 38, 48-54. http://www.jdir.org/journal/view.html?uid=411\&vmd=Full\&

[12] Nair, C., Bharathi, S., Jawade, R. and Jain, M. (2013) Basal Implants-A Panacea for Atrophic Ridges. Journal of Dental Sciences \& Oral Rehabilitation, 1-4.

[13] Stefan, I. (2005) Principles of BOI Clinical, Scientific, and Practical Guidelines to 4-D Dental Implantology. Springer, Heidelberg. https://doi.org/10.1007/b138420

[14] Rahul, S., Jai, P., Dhruv, A. and Anurag, H. (2016) Basal Implants-An Alternate Treatment Modality for Atrophied Ridges. International Journal of Research in Dentistry, 6, 60-72.

[15] Grishmi, N. and Mitul, M. (2017) Basal Implants-A Remedy for Resorbed Ridges. World Journal of Pharmaceutical and Life Sciences, 3, 565-572.

[16] Shahed, S.S.A., Nagaral, S.C. and Mujawar, A.M. (2018) Basal Implants: A Breakthrough for Atrophic Ridges: Review. Journal of Applied Dental and Medical Sciences, 4, 2454-2288.

[17] Ahmad, O. and Thamer, B. (2014) Basal Screw Implantology without Sinus Lifting. Pakistan Oral \& Dental Journal, 34, 414-416.

[18] Mayur, K. and Vivek, G. (2015) Evidence of Bone Formation in the Nasal Floor around Polished Surface Bi-Cortical Screw Implants after Indirect Nasal Lift in an Atrophied Maxilla: Cone Beam Computed Tomography-Based Case Report. Journal of Indian Society of Periodontology, 19, 236-238. https://doi.org/10.4103/0972-124X.149941

[19] Stefan, I. and Miroslav, E. (2004) Case Report: Restoration of Edentulous Mandible with 4 BOI Implants in and Immediate Load Procedure. Biomed Papers, 148, 
195-198. https://doi.org/10.5507/bp.2004.036

[20] Advantages of Immediate Loading Basal Implants.

http://www.dentalimplantskerala.com

[21] Disadvantages of Basal Implants.

http://drmurugavel.in/content/boi-dental-implants-india-basal-dental-implants-india

[22] Sharma, N.J. (2017) Maxillofac. Oral Surgery, 16, 506.

https://doi.org/10.1007/s12663-016-0977-4 